\title{
Feeding behavior of two ommastrephid squids Ommastrephes bartramii and Sthenoteuthis oualaniensis off Hawaii
}

\author{
Matthew Parry* \\ Pacific Islands Regional Office, National Oceanic and Atmospheric Administration, 1601 Kapiolani Boulevard, \\ Suite 1110 Honolulu, Hawaii 96814-0047, USA
}

\begin{abstract}
The feeding behaviors of squids Ommastrephes bartramii $(\mathrm{n}=315)$ and Sthenoteuthis oualaniensis $(\mathrm{n}=280)$, collected during yearly 2 wk cruises from 1996 to 2001, were compared. Fish and squid prey dominated the stomach contents and were identified from otoliths and beaks, respectively. A total of 2561 otoliths and 424 beaks were recovered; $84 \%$ of $O$. bartramii stomachs contained otoliths while $54 \%$ contained cephalopod beaks. For S. oualaniensis, $75 \%$ of stomachs contained otoliths while $34 \%$ contained cephalopod beaks. Myctophidae were the most prevalent fish prey item for both species in frequency and abundance; however, $O$. bartramii fed on a wider range of prey items than $S$. oualaniensis at the family and species level. The myctophid Symbolophorus evermanni was a substantial prey item for both species. Both predators fed substantially on the squid families Onychoteuthidae and Enoploteuthidae, but $O$. bartramii fed on a wider range of squid prey items than S. oualaniensis. Levins' (1968; 'Evolution in changing environments', Princeton University Press) standardized measure of niche breadth was greater for $O$. bartramii than for $S$. oualaniensis when calculated using either otoliths (0.56 vs. 0.086) or beaks (0.22 vs. 0.097). MacArthur \& Levins' (1967; Am Nat 101:377-385) measure of niche overlap of $S$. oualaniensis on $O$. bartramii was greater than that of $O$. bartramii on $S$. oualaniensis, for both fish otoliths (1.16 vs. 0.22$)$ and squid beaks (0.93 vs. 0.46). These results suggested that $O$. bartramii is a more generalized predator than $S$. oualaniensis. Competition for food resources appears low between $O$. bartramii and $S$. oualaniensis where they overlap in the North Pacific.
\end{abstract}

KEY WORDS: Ommastrephidae - Squid · Feeding behavior · Hawaii - Ommastrephes bartramii Sthenoteuthis oualaniensis $\cdot$ Myctophidae $\cdot$ Trophic ecology $\cdot$ Otoliths $\cdot$ Beaks Resale or republication not permitted without written consent of the publisher

\section{INTRODUCTION}

Ommastrephes bartramii and Sthenoteuthis oualaniensis (order Teuthoidea, suborder Oegosida, family Ommastrephidae) are large fast moving squids that are key members of the pelagic ecosystem (Roper et al. 1984). They prey on a wide range of meso- and epipelagic species and are prey for large predators such as swordfish, sharks, tuna, cetaceans and many others (King \& Ikehara 1956, Okutani et al. 1976, Seki 1993, Watanabe et al. 2004).

The feeding behaviors of both species have been previously investigated in some habitats. Seki (1993) did some general stomach contents analyses of Omma- strephes bartramii, but did not categorize the prey items past family in most cases. Watanabe et al. (2004) looked at feeding habits of $O$. bartramii in the transitional region of the North Pacific, where it preyed heavily on mid-water fishes and squids. Shchetinnikov (1992) studied feeding of Sthenoteuthis oualaniensis in the Eastern Pacific and found that they preyed heavily on young Dosidicus gigas, a member of the same subfamily. A single brief study looked at the feeding habits of both of these species simultaneously (Dunning \& Brandt 1985), but to date no studies have done so in the Central North Pacific.

In the Central North Pacific the distributions of Ommastrephes bartramii and Sthenoteuthis ouala- 
niensis overlap during the winter when $O$. bartramii migrates south to spawn. In Hawaiian waters, the mean size of $S$. oualaniensis commonly caught at jigging stations is about $40 \%$ of the mantle length (ML) of the smallest $O$. bartramii females (Young \& Hirota 1998). This size difference places much of the $S$. oualaniensis population well within the size range of potential squid prey for $O$. bartramii. Because $O$. bartramii and $S$. oulaniensis are members of the same subfamily, heavy predation by one on the other is expected (see Shchetinnikov 1992).

Trophic interactions between these 2 species - such as those between a predator and prey or between competitors - could strongly affect their life histories. This feeding study of Ommastrephes bartramii and Sthenoteuthis oualaniensis, conducted in the Central North Pacific where their populations overlap, was designed to determine if such interactions (i.e. predation or competition for food resources) occur and, if so, how they might affect life history patterns of these squids.

\section{MATERIALS AND METHODS}

Dietary measurements. Niche breadth was used to quantify the degree of specialization to which a squid utilizes available resources (see Krebs 1989, Cortes et al. 1996, Heithaus 2001). Resource states (based on prey taxa) were used in this study. Levins' (1968) measure of niche breadth was used to measure uniformity in the distribution of prey items among all prey categories. For ease of comparison, Levins' (1968) measure was standardized to a scale from 0 (minimum niche breadth) to 1 (maximum niche breadth) according to Hurlbert (1978).

MacArthur \& Levins' (1967) measure was used to calculate resource overlap between the squid species. MacArthur \& Levins' (1967) measure has been used effectively to determine resource overlap (e.g. Macpherson 1981, Ellis et al. 1996, Heithaus 2001), and was used here because initial assumptions were that there would be asymmetrical overlap between Ommastrephes bartramii and Sthenoteuthis oualaniensis. Measures of resource overlap impart varying degrees of bias depending on differing numbers of resource categories, differences in sample sizes among species being compared, and resource evenness (Krebs 1989).

Cruises. Most specimens were collected during 6 cruises that were conducted aboard FTS 'Hokusei Maru' during the years between 1996 and 2001 (inclusive), with each cruise starting on 5 February and ending on 20 February. This study evolved as a subset of an original study on the general ecology of Ommastrephes bartramii. Cruise tracks differed each year but were generally located between 172 and $158^{\circ} \mathrm{W}$ longitude, and 18 and $32^{\circ} \mathrm{N}$ latitude (Fig. 1). The general plan of each cruise was to proceed north to the beginning of the Subtropical Frontal Zone (usually located near $30^{\circ} \mathrm{N}$ ) where the abundance of $O$. bartramii is high, and then move south towards the main islands of the Hawaiian archipelago where the abundance of O. bartramii decreases while that of Sthenoteuthis oualaniensis increases.

Additional samples were collected during 2 cruises aboard the RV 'Townsend Cromwell' conducted in November and January of 1999, in connection with the National Marine Fisheries Service (NMFS) Pacific Islands Fisheries Science Center.

Sample collection. Ommastrephid squids: Squids were predominantly caught using pole and line jigging. Fishing operations began roughly around 21:00 h and usually continued until 04:00 $\mathrm{h}$, depending on conditions. Each fishing station was conducted as a drift station with the ship's engine shut down in order to minimize disturbance.

Pole and line jigging was conducted by between 3 and 8 people per station using fishing poles rigged with 20 pound test lines and a variety of sizes of squid jigs ranging from small to large (5 to $15 \mathrm{~cm}$ ).

Potential prey: Potential prey of Ommastrephes bartramii and Sthenoteuthis oualaniensis were collected

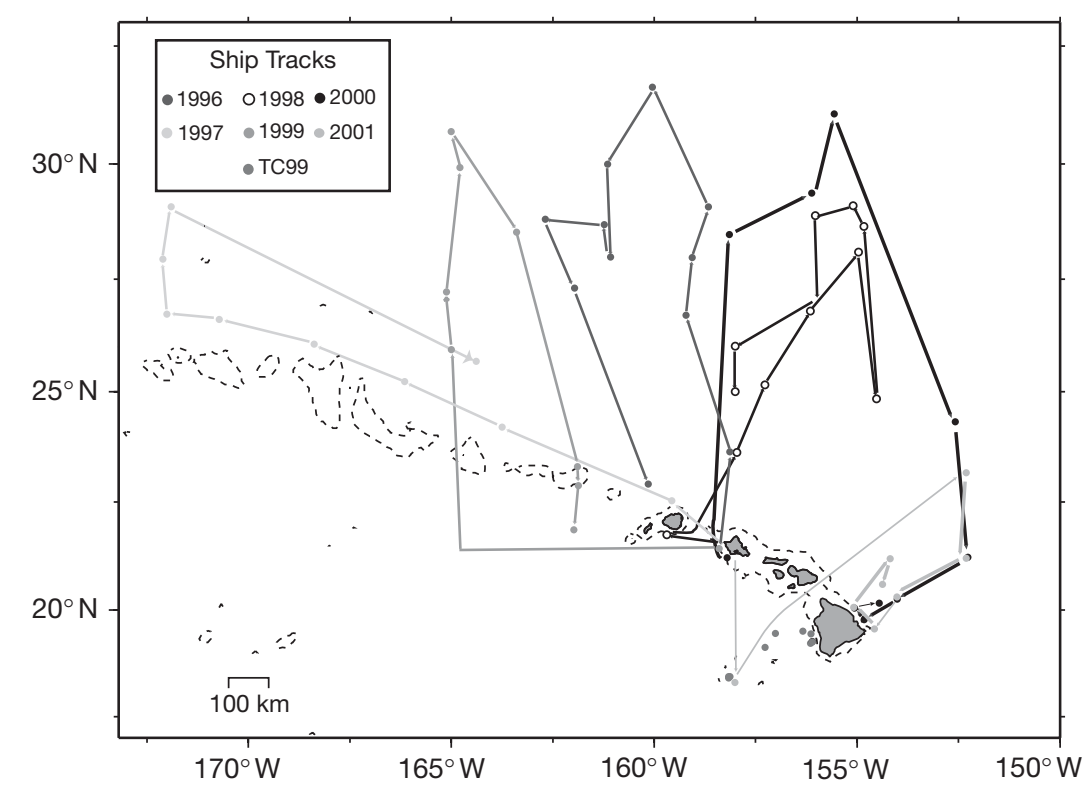

Fig. 1. Ship tracks of yearly cruises from 1996 to 2001 aboard FTS 'Hokusei Maru' and stations of 2 cruises in 1999 aboard RV 'Townsend Cromwell' 
by trawl on all 6 of the FTS 'Hokusei Maru' cruises. During the years 1996 to 1999, mesopelagic fishes and squids were captured using a large midwater otter trawl. The trawl had an operational rectangular mouth opening of $200 \mathrm{~m}^{2}$. One or 2 tows at $800 \mathrm{~m} \mathrm{(1} \mathrm{h} \mathrm{at} \mathrm{depth}$ for each tow) were made at every station during the daytime, weather permitting.

Sample manipulation and preparation. Ommastrephid squids: Mantle length $(\mathrm{ML}$, measured from the dorsal anterior free mantle margin to the posterior end of the mantle), sex, and species were determined onboard for all jig-caught squids during all cruises. Stomach contents were removed and any excess water was blotted before contents were weighed. After weighing, contents were placed into a $333 \mu \mathrm{m}$ Nitex strainer and rinsed with running water. The contents were then examined under a dissection microscope for identifiable parts. To identify prey items within the stomachs, fish otoliths and cephalopod beaks were removed and stored separately in $100 \%$ ethanol or $50 \%$ isopropanol, respectively, for later identification. Only sagittal otoliths were retained from the stomachs of the squids, and these were compared with sagitta in an otolith library formed from fish caught during the cruises. Cephalopod beaks recovered from the stomachs of the squids were also identified by comparisons to a library of beaks.

Levins' (1968) measure of niche breadth was calculated separately for otoliths and beaks recovered in the stomachs of both squid species. Fish and squid prey, the 2 major sources of food for these squids, were considered separately to examine potential feeding differences. Each value was then standardized using the method of Hurlbert (1978). Otolith and beak data were also used to calculate MacArthur \& Levins' (1967) measure of niche overlap for both species and for each species. When calculating niche breadth only otoliths and beaks that could be identified were used, and categories were assigned to the lowest identifiable taxon.

The number of resource categories was determined as the total number of resources (fishes or squids) that were represented in all of the stomachs of both squid species during the entire study. This was assumed to be the number of resource categories, even though other fish and squid resource categories (not represented in the stomachs sampled) probably exist. These data use the same categories of prey to calculate the standardized niche breadth for feeding in each species; this process does not take into account the fact that there may be other potential prey categories that were not represented in the individuals sampled. Given the sample sizes caught for each squid, most of the prey categories were probably represented.

Potential prey: Only specimens in good condition (i.e. photophores mostly intact, body mostly intact etc.) were kept and frozen at $-20^{\circ} \mathrm{C}$.
Fishes caught in the trawls were taken back to the lab and identified to the lowest possible taxon. Fishes in the family Myctophidae were generally classified to species level where possible, whereas other fishes were usually only categorized to the family level. All fish caught in good condition during the years 1996 to 1998 were used as the basis for the otolith library. The otoliths (sagitta, asteriscus, and lapillus) of all fish were removed, cleaned of debris, and placed in cardboard microslide containers covered with glass. Otoliths were collected from a total of 250 fish comprising 20 separate fish families; 17 species of myctophids were included in the library.

\section{RESULTS}

\section{General}

Over the 6 years of this study, 315 Ommastrephes bartramii were captured, comprising 263 males (84\%) and 52 females $(16 \%)$. Mean ML of male O. bartramii was $329 \mathrm{~mm}$ (SD = $25 \mathrm{~mm})$, compared to mean $535 \mathrm{~mm}$ ( $\mathrm{SD}=41 \mathrm{~mm}$ ) for females. A total of 280 Sthenoteuthis oualaniensis were caught: 38 males (14\%) and 242 females (86\%). Male $S$. oualaniensis had a mean ML of $155 \mathrm{~mm}(\mathrm{SD}=15 \mathrm{~mm})$, whereas mean female ML was $198 \mathrm{~mm}(\mathrm{SD}=40 \mathrm{~mm})$. The numbers of $O$. bartramii caught during the 6 years of sampling were: (1996) 71, (1997) 68, (1998) 63, (1999) 81, (2000) 11, (2001) 21. The numbers of $S$. oualaniensis caught during the 6 years of sampling were: (1996) 6, (1997) 19, (1998) 101, (1999) 59, (2000) 44, (2001) 51.

A stomach was considered empty if there was no weighable material (i.e. $<0.001 \mathrm{~g}$ on the scales used). Of the Ommastrephes bartramii stomachs examined, $28(9 \%)$ were empty, whereas $56(20 \%)$ of Sthenoteuthis oualaniensis stomachs were empty.

Fish and cephalopod remains dominated the stomach contents; on rare occasions decapod crustacean remains were found, but in such small and unidentifiable portions that they were ignored. A total of 2561 otoliths and 424 beaks were recovered during this study. For Ommastrephes bartramii, otoliths were found in 264 (84\%) stomachs, and 169 (54\%) stomachs contained cephalopod beaks. For Sthenoteuthis oualaniensis, otoliths were found in 211 (75\%) stomachs, while beaks were found in $96(34 \%)$ stomachs. The fish otoliths recovered from the stomachs of both squid species were categorized into 17 families. Of these 17 families, otoliths from members of Myctophidae, Anoplogasteridae, and Omosudidae were identified to species level. Within the Myctophidae, 16 species were identified. Otoliths of 4 common species of myctophids could not be identified to species level: Hygophum proximum could not be distinguished 
from $H$. rheinhardti, and Myctophum lychnobium could not be distinguished from $M$. spinosum. These 4 species were placed into 2 species groups (H. proximum/rheinhardti and M. lychnobium/spinosum). The beaks found in the stomachs of both species of squids represented 18 families of cephalopods, from which 29 genera and 8 species were identified. Otoliths or beaks occurring at $<1 \%$ frequency in both species were ignored; similarly, otoliths or beaks which contributed $<1 \%$ to total abundance in both species were ignored. In 15 of the O. bartramii stomachs, mesh-like masses of gelatinous tissue were found that were possibly the remains of pyrosomes, but these could not be identified conclusively. One $O$. bartramii stomach was filled with an egg mass from a pelagic octopus, probably Argonautasp.

\section{Otolith data from Ommastrephes bartramii}

Frequency data

Otoliths belonging to the family Myctophidae were found in $63 \%$ of Ommastrephes bartramii stomachs, with unidentified otoliths the next most frequent group of prey $(37 \%)$ followed by otoliths from Gonostomatidae (16\%) (Fig. 2A). Otoliths from 7 families of fishes occurred at frequencies greater than or close to $5 \%$ (Fig. 2A). Otoliths from 8 species/species groups within the family Myctophidae were found at high (>5\%) frequencies, while 6 other myctophid species/species groups were found at frequencies $>1 \%$ (Fig. 2B).

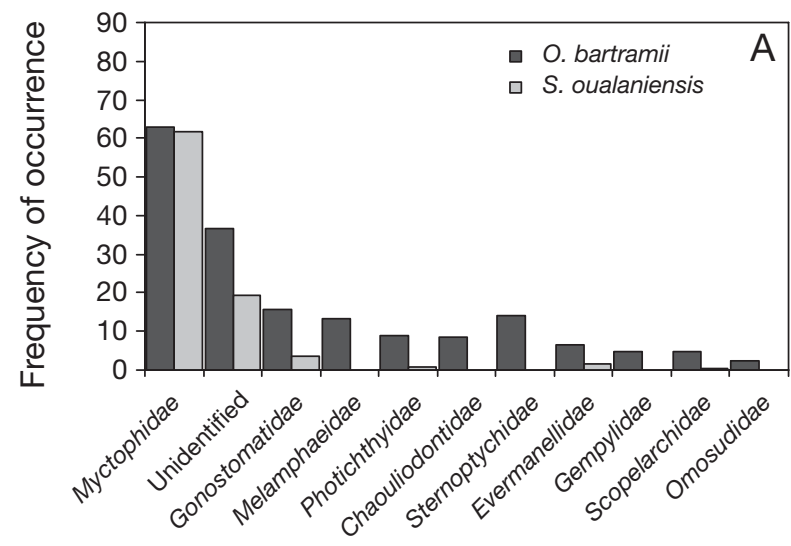

Fish family

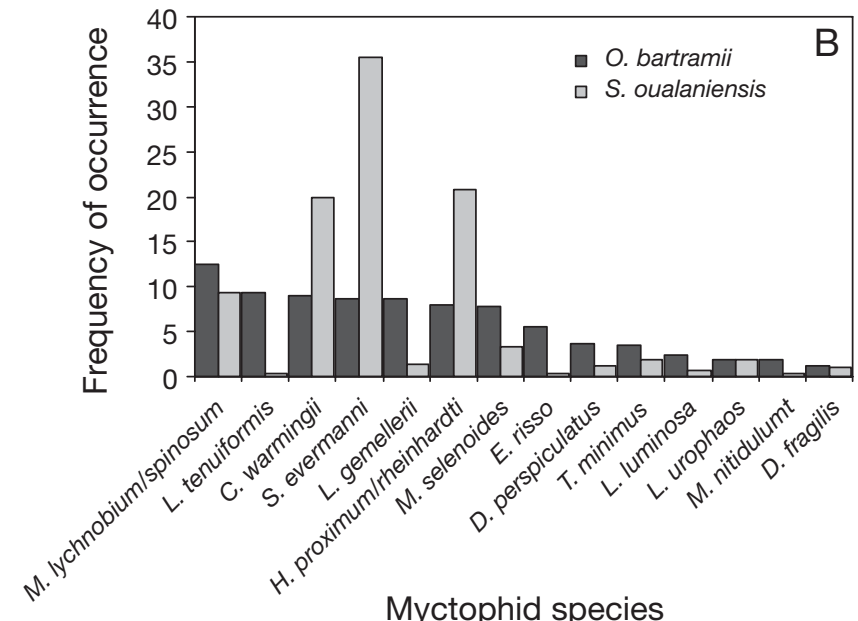

Myctophid species

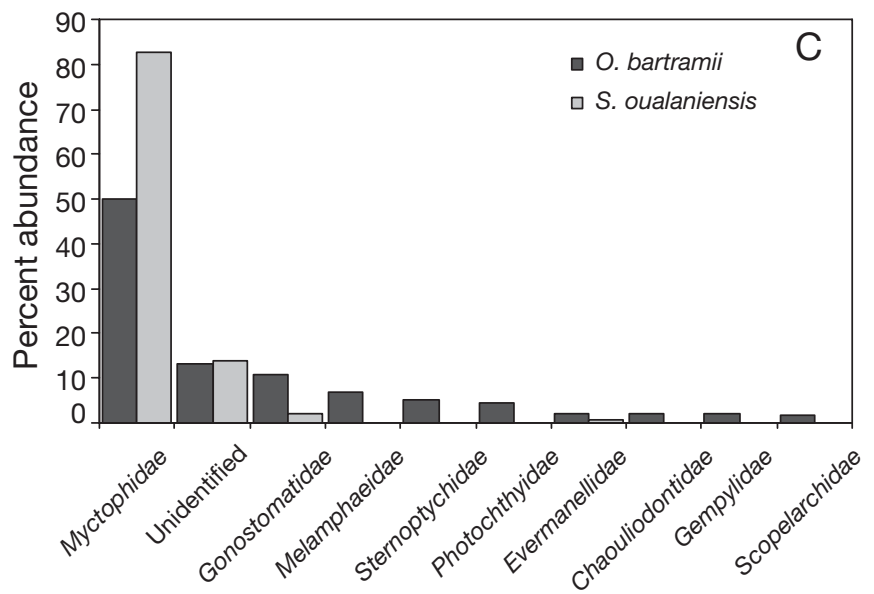

Fish family

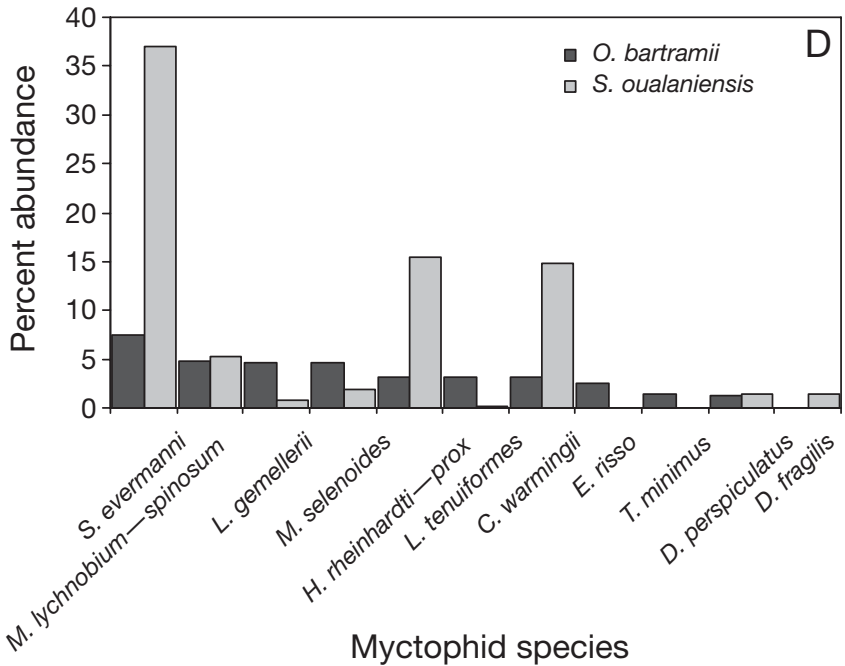

Fig. 2. Ommastrephes bartramii and Sthenoteuthis oualaniensis. Stomach contents data: frequency occurrence of otoliths from (A) fish families and (B) species of Myctophidae; percent abundance of otoliths from (C) fish families and (D) species of Myctophidae 
Abundance data

A total of 1624 otoliths were recovered from Ommastrephes bartramii stomachs. Of these, 50\% came from myctophids, while unidentified otoliths contributed $13 \%$ (Fig. 2C). The 3 next most abundant family categories of otoliths represented Gonostomatidae (11\%), Melamphaeidae (7\%), and Sternoptychidae (5\%) (Fig. 2C). The remaining $14 \%$ of otoliths belonged to the families Photichthyidae, Evermanellidae, Chauliodontidae, Gempylidae, and Scopelarchidae. Of the otoliths from Myctophidae, those of Symbolophorus evermanni were most abundant (7.5\% of all otoliths), while Myctophum lychnobium/spinosum, Lobianchia gemellerii, and Myctophum selenoides were all recovered at similar abundances ( 5\%) (Fig. 2D).

\section{Otolith data from Sthenoteuthis oualaniensis}

\section{Frequency data}

Myctophid otoliths were recovered from $62 \%$ of Sthenoteuthis oualaniensis stomachs, while unidentified otoliths were found in $19 \%$ of stomachs and gonostomatid otoliths in $4 \%$ of stomachs (Fig. 2A). Otoliths from 3 species/species groups within Myctophidae ( $S$. evermanni, Ceratoscopelus warmingii, and Hygophum proximum/rheinhardti) occurred at frequencies greater than or close to $20 \%$, while 7 other species within Myctophidae occurred at frequencies $>1 \%$ (Fig. 2B). The only other otoliths that occurred at a frequency greater than $1 \%$ were from Evermanellidae (1.65\%) (Fig. 2A).

\section{Abundance data}

From the 937 otoliths recovered from Sthenoteuthis oualaniensis stomachs, $83 \%$ came from myctophids while $14 \%$ were unidentified (Fig. 2C). The remaining $3 \%$ of otoliths belonged to Gonostomatidae and Evermanellidae. Of the otoliths from Myctophidae, Symbolophorus evermanni was the most abundant species identified (37\%), followed by C. warmingii and Hygophum proximum/rheinhardti (both $15 \%$ ), and Myctophum lychnobium (5\%) (Fig. 2D).

\section{Beak data from Ommastrephes bartramii}

\section{Frequency data}

At the family level, the most common beaks in stomachs from Ommastrephes bartramii were Onychoteuthidae $(14 \%)$, followed by Histioteuthidae, Enoploteuthi- dae, and unidentified beaks that were foundat similar frequencies (10 to $12 \%$ ). Ommatrephidae and Pyroteuthidae both occurred in $5 \%$ of stomachs, whereas all other family categories of beaks occurred at frequencies $<5 \%$ (Fig. 3A). When the beaks were categorized to the lowest possible taxa, Onychoteuthis sp. occurred most frequently $(14 \%)$, followed by Histioteuthis sp. and unidentified beaks (10\%), and then Abraliopsis sp. A and Pyroteuthis addolux (5\%). All the other beak categories had frequencies below $3 \%$ (Fig. 3B).

\section{Abundance data}

A total of 288 cephalopod beaks were recovered from the Ommastrephes bartramii stomachs. At the family level, beaks of Onychoteuthidae were most abundant $(24 \%)$. Beaks of Histioteuthidae, Ommastrephidae, and Enoploteuthidae were all recovered at similar abundances (10 to $12 \%$ ) (Fig. 3C). When beaks were categorized to the lowest possible taxa, Onychoteuthis sp. accounted for $24 \%$ of beaks, followed by Histioteuthis sp. (12\%). Pyroteuthis addolux and Abraliopsis sp. A both accounted for similar percentages $(6 \%)$ of the beaks. Another 9 categories of beaks were recovered at varying frequencies between 2 and $3 \%$ (Fig. 3D).

\section{Beak data from Sthenoteuthis oualaniensis}

Frequency data

Enoploteuthidae occurred most frequently at the family level in Sthenoteuthis oualaniensis stomachs (17\%), followed by Onychoteuthidae (10\%), while Ommastrephidae and unidentified beaks occurred at similar frequencies ( $5 \%$ ) (Fig. 3A). When beaks were categorized to the lowest possible taxa, Abraliopsis sp A. occurred most frequently (12\%), followed by Onychoteuthis sp. (10\%), and Enoploteuthis sp. and Abraliopsis sp. ( 2\%) (Fig. 3B).

Abundance data

In total, 136 cephalopod beaks were recovered from Sthenoteuthis oualaniensis stomachs. At the family level, beaks of Enoploteuthidae were most abundant $(46 \%)$, followed by Onychoteuthidae (22\%), unidentified beaks $(12 \%)$, and Ommastrephidae (11\%) (Fig. 3C). When beaks were categorized to the lowest possible taxa, Abraliopsis sp. A, and Onychoteuthis sp. occurred most frequently, accounting for 33 and $22 \%$ of beaks, respectively (Fig. 3D). Other Abraliopsis spp. accounted for $7 \%$ of beaks, while 3 other genera occurred at abundances $<3 \%$ (Fig. 3D). 

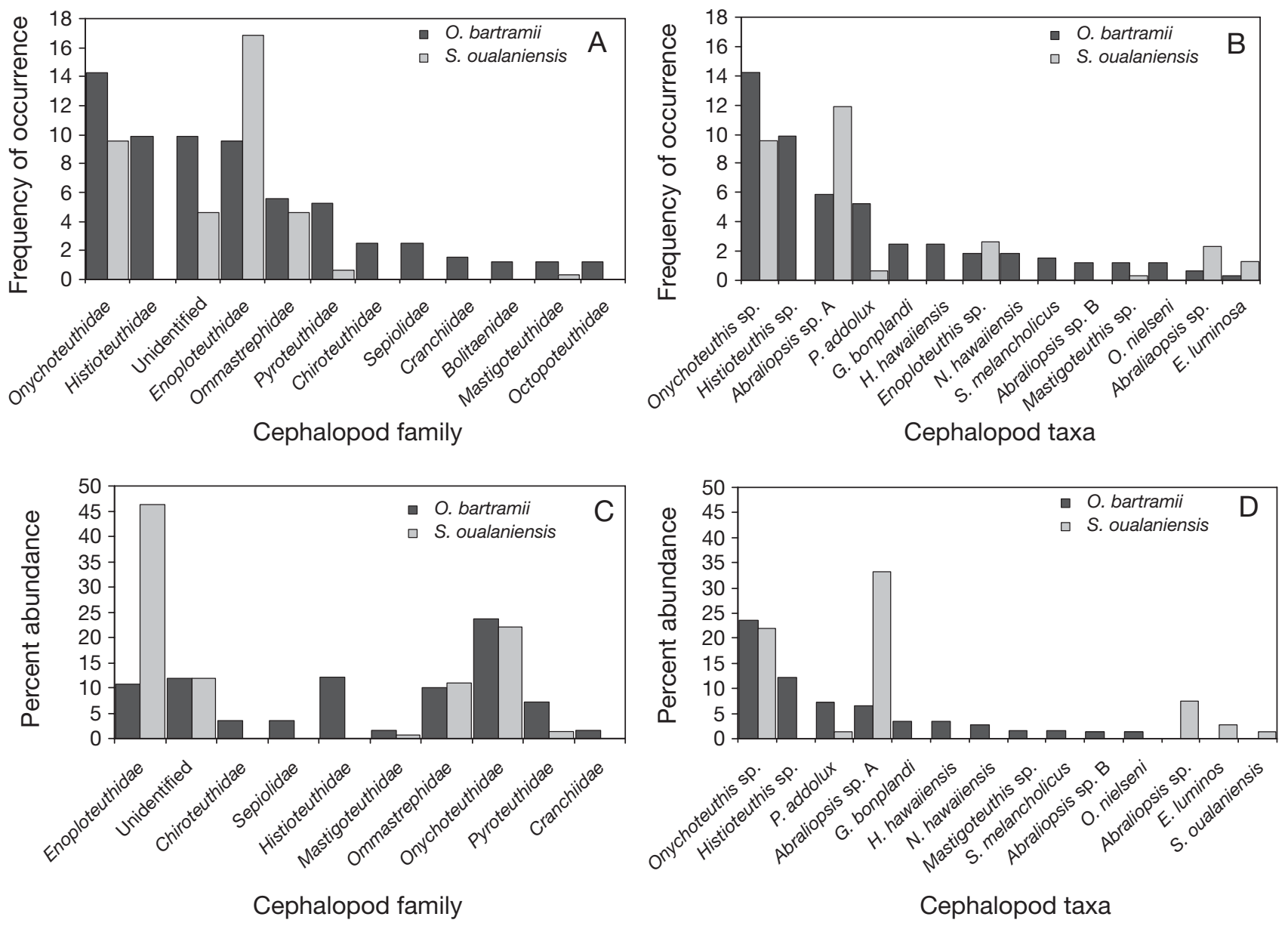

Fig. 3. Ommastrephes bartramii and Sthenoteuthis oualaniensis. Stomach contents data: frequency occurrence of beaks from (A) cephalopod families and (B) cephalopod taxa; percent abundance of beaks from (C) cephalopod families and (D) cephalopod taxa

\section{Ommastrephid prey remains}

\section{Ommastrephes bartramii}

Three freshly consumed Ommastrephes bartramii were identified in $O$. bartramii stomachs. Another 16 unidentified ommastrephid squids were found, 15 of which consisted of freshly consumed material such as arms and tentacles. The freshly consumed materials were considered to be artifacts because $O$. bartramii were frequently seen attacking others that had been hooked, and there were numerous pieces of caught animals (arms, tentacles) lost overboard during fishing.

\section{Sthenoteuthis oualaniensis}

The remains of 2 Sthenoteuthis oualaniensis were identified in $S$. oualaniensis stomachs: 1 was fresh, while the other appeared to have been consumed at a significant time prior to capture. No Ommastrephes bartramii were found in $S$. oualaniensis stomachs; however, 16 unidentified ommastrephid squids were found, 13 of which consisted of freshly consumed material such as arms and tentacles. Again, these materials were considered to be artifacts from the numerous pieces of caught animals (arms, tentacles) lost overboard during fishing. The beaks of 5 Eucleoteuthis luminosa and 6 Nototodarus hawaiiensis were also identified in the stomachs of this species. These 2 species comprised the remainder of the total identified ommastrephid material.

\section{Niche breadth and overlap}

Levin's (1968) standardized niche breadth for Ommastrephes bartramii was 0.56 when using otolith data, and 0.22 when using beak data. Standardized niche breadth for Sthenoteuthis oualaniensis was 0.086 when using otolith data, and 0.097 when using beak data.

MacArthur \& Levins' (1967) niche overlap of Sthenoteuthis oualaniensis on Ommastrephes bartramii was 
1.16 when using otolith data and 0.93 when using beak data. Niche overlap of $O$. bartramii on $S$. oualaniensis was 0.22 when using otolith data and 0.46 when using beak data.

\section{DISCUSSION}

Determining the feeding behaviors of these wideranging open ocean squid is difficult given present limitations of the data. In addition, the habitat virtually excludes experimental manipulation. Zuev et al. (1975; quoted in Shchetinnikov 1992) states 'the systematic and ecological similarity of [Sthenoteuthis oualaniensis, Ommastrephes bartramii, and other ommastrephids] has led to division of the open ocean...through interspecific competition.' If so, one might expect these species to show strong competitive interactions in areas of sympatry.

The proportions and frequencies of items in the diets of Ommastrephes bartramii and Sthenoteuthis oualaniensis, as well as the dietary measurements calculated from these values, indicate that although $S$. oualaniensis feeds on a subset of the $O$. bartramii diet, their feeding patterns are basically different. Ommastrephes bartramii feeds on a broader selection of species than $S$. oualaniensis, and feeds more evenly across these categories. Not only does $O$. bartramii feed more broadly than $S$. oualaniensis on fishes and squids at the family level, it also feeds more generally at the species level. In addition, direct predatory interactions between these species were not observed. This finding was unexpected because it was contrary to studies in other areas, which have shown substantial feeding on closely related squids in this family with comparable size differences. Otherwise, the diets of both squids were in good agreement with results from other studies that have looked at these species separately, and argue against a possible niche shift when they are located together geographically.

Apparently, competition for food resources is low where the populations of Ommastrephes bartramii and Sthenoteuthis oualaniensis overlap in the Central North Pacific. These dietary differences could be the result of resolved competition, or simply due to the size difference between these 2 species. However, the separation of known peaks in breeding seasons argues that the apparent lack of direct interaction and/or competition for food resources between $O$. bartramii and $S$. oualaniensis is the result of past competition.

Acknowledgements. I thank R. E. Young for his guidance and input on all aspects of this study. I am grateful to the captains, officers, and crew of FTS 'Hokusei Maru' and RV 'Townsend Cromwell' for all of their help and hard work collecting specimens, and am also grateful to Dr. R. Bidigare, Dr. B. Popp, Dr.
J. Polovina, and Dr. D. Greenfield. This project was supported by a Pelagic Fisheries Research Program grant and I thank Dr. J. Sibert for his assistance. Finally, I thank the University of Hawaii Hilo for providing undergraduate volunteers for field work, and Dr. C. Measures for his continued assistance throughout this process.

\section{LITERATURE CITED}

Cortes E, Manire CA, Hueter RE (1996) Diet, feeding habits, and diel feeding chronology of the bonnethead shark Sphyrna tiburo, in southwest Florida. Bull Mar Sci 58: 353-367

Dunning M, Brandt SB (1985) Distribution and life history of deep-water squid of commercial interest from Australia. Aust J Mar Freshw Res 36:343-359

Ellis JR, Pawson MG, Shackley SE (1996) The comparative feeding ecology of six species of shark and four species of ray (Elasmobranchii) in the north-east Atlantic. J Mar Biol Assoc UK 76:89-106

Heithaus MR (2001) Predator-prey and competitive interactions between sharks (order Selachii) and dolphins (suborder Odontoceti): a review. J Zool 253:53-68

Hurlbert SH (1978) The measurement of niche overlap and some relatives. Ecology 59:67-77

King JE, Ikehara JJ (1956) Comparative study of food of bigeye and yellowfin tuna in the Central Pacific. Fish Bull 57: 61-85

Krebs CJ (1989) Ecological methodology. Harper Collins, New York

Levins R (1968) Evolution in changing environments. Princeton University Press, Princeton, NJ

MacArthur RH, Levins R (1967) The limiting similarity, convergence, and divergence of coexisting species. Am Nat 101:377-385

Macpherson E (1981) Resource partitioning in a Mediterranean demersal fish community. Mar Ecol Prog Ser 4: 183-193

Okutani T, Satake Y, Ohsumi S, Kawakami T (1976) Squids eaten by sperm whales caught off Joban district, Japan during January-February 1976. Bull Tokai Reg Fish Res Lab 87:67-113

Roper CFE, Sweeney MJ, Nauen CE (1984) FAO species catalogue. Vol. 3: Cephalopods of the world. An annotated and illustrated catalogue of species of interest to fisheries. FAO Fish Synop 125

Seki MP (1993) Trophic relationships of Ommastrephes bartramii during winter migrations to subtropical waters north of the Hawaiian islands. In: Okutani T, O'Dor RK, Kubodera T (eds) Recent advances in cephalopod fisheries biology. Tokai University Press, Tokyo, p 523-529

Shchetinnikov AS (1992) Feeding spectrum of squid Sthenoteuthis oualaniensis (Oegopsida) in the Eastern Pacific. J Mar Biol Assoc UK 72:849-860

Watanabe H, Kubodera T, Ichii T, Kawahara S (2004) Feeding habits of neon flying squid Ommastrephes bartramii in the transitional region of the central North Pacific. Mar Ecol Prog Ser 266:173-184

Young RE, Hirota J (1998) Review of the ecology of Sthenoteuthis oualaniensis near the Hawaiian Archipelago. Int Symp on large pelagic squids, Japan Marine Fishery Resources Research Center, Tokyo

Zuev GV, Nesis KN, Nigmatullin CM (1975) System and evolution of the squid genera Ommastrephes and Symplectoteuthis (Cephalopoda, Ommastrephidae). Zool Zh 54: 1468-1480 